\title{
The effect of emotional intelligence on organizational commitment: Understanding the me- diating role of job satisfaction
}

\author{
Abdulrahman Alsughayir ${ }^{*}$
}

${ }^{a}$ School of Economics \& Administrative Science, Al Imam Muhammad ibn Saud Islamic University, Riyadh 11431, Saudi Arabia

\section{H R O N I C L E}

Article history:

Received: July 10, 2020

Received in revised format:

October 182020

Accepted: November 6, 2020

Available online:

November 11, 2020

Keywords:

Emotional Intelligence

Organizational Commitment

Job Satisfaction

\section{A B S T R A C T}

\begin{abstract}
This study aims to analyze how emotional intelligence (EI) influences organizational commitment along with the correlation between job satisfaction and these two aspects. To collect the data for this study, a polite and pre-validated, self-structured questionnaire was used. Additionally, ethical issues were considered with the assurance of anonymity. The study also took the convenience sampling approach and collected samples from customer service employees working in all main branches of Saudi banks located in Riyadh. It further employs the structural equation modeling method for analyzing the data with AMOS 22.0 software. Before examining the structural model framework and hypotheses, a confirmatory factor analysis was used to estimate the measurement model and support the research. Results showed that emotional intelligence affects both job satisfaction and organizational commitment significantly and positively. Moreover, results showed that job satisfaction, as a mediator, has a significant indirect impact on EI and organizational commitment. Emotionally intelligent customer service employees of Saudi commercial banks demonstrated high psychological empowerment visible through their perception of work as meaningful, increased feeling of competence, guaranteed freedom of choice, and significant impact on the workplace.
\end{abstract}

(C) 2021 by the authors; licensee Growing Science, Canada

\section{Introduction}

Emotions are an important part of life and play a significant role in work and social culture of individuals. They are the states of feelings that can greatly affect the antecedents of behaviors including attitudes, attributions, and perceptions. Cooper and Sawaf (1999) explained emotions as the flow of energy that affects an individual's behavior and spreads around and influences others. According to Fredrickson (2001), it is difficult to imagine an unorganized society with insensitive human beings and unmanned organizations, and therefore, the role of emotions in human life remains significant. Moreover, such significance has resulted in the rise of the emotional intelligence concept. In recent times, researchers and psychologists are taking a keen interest in understanding the role of emotions in workplaces. Moreover, the role has been considered a monumental shift in organizational behavior (Barsade \& Spataro, 2003). However, the sudden spike in interest is still at its nascent stage and several areas are not only recommended for but also require further theoretical extensions and empirical analyses (Brief \& Weiss, 2002). Salovey and Mayer (1989) proposed EI as an ability of human emotions. It is particularly described as the ability of an individual to identify, perceive, understand, and manage his/her emotions as well as other people's (Mayer \& Salovey, 1997; Mayer \& Caruso, 2004). Studies have shown that higher the level of emotional intelligence, better the ability to process affective information (Brackett \& Salovey, 2006). This suggests that people with a higher level of emotional intelligence can tolerate - or productively use - both positive and negative emotions at a significant level.

* Corresponding author. Tel: 966-11258-5555

E-mail address: aaalsughayir@yahoo.com (A. Alsughayir) 
Emotional intelligence was first addressed by an American psychologist Edward Thorndike during the early 90s, and it is considered a sub-branch of social intelligence (Mayer \& Salovey, 1993). Today, it is emerging as a topic of interest among researchers around the world. Besides, the increased rate of studies around the issues of emotional intelligence (Zeidner et al., 2004 ) is proof of its widespread popularity in recent times. In general, management, psychology, and studies of other disciplines put emphasis on the improvement of emotional intelligence - an essential concept in work and social life. Moreover, in various studies, emotional intelligence is considered to be more important than mental intelligence (Aki et al., 2003). According to these studies, mental intelligence is not enough for an individual to succeed in both work and life, and people limited to such intelligence are regarded as machines. Similarly, Goleman, in his studies, argues that emotional intelligence is one of important keys to success in life results from emotional intelligence.

Emotional interactions are inevitable, especially in-service industries such as schools, hospitals, accommodations, and banks. In the banking and financial service sector, competition remains at its peak (Dou et al., 2018; Papadimitri et al., 2019). Here, a key to maintain a distinct competitive edge is not just about service packages but how these services are provided by customer service employees (Cooke et al., 2019). Customers, in general, place a high priority on their interactions with the employees, thereby making emotional intelligence a key factor in the competition (Mattingly \& Kraiger, 2018). Despite a strong correlation between emotional intelligence, emotional requirements for a job, and outcomes (Jordan, Ashkanasy, \& Hartel, 2002), such a connection has not been studied widely. Even rarer are attempts to analyze these three constructs together in various fields such as law enforcement and healthcare. To that end, this research is aimed at addressing this gap by examining the impact of Emotional Intelligence in relation to the emotional components of a job, job attitudes, and productive outcomes. This study intends to provide aid to the banking and financial service sector through its customer service employees by examining how the emotional intelligence of these employees influences their job attitudes.

The domain of the proposed research will be the operating banks in the Kingdom of Saudi Arabia, an economic powerhouse in the Middle East and one of the G20 countries. Saudi's financial market is headed towards a more global approach as a result of the Kingdom's direction towards "vision 2030" (Kamarudin et al., 2018). However, in many cases, customers in the country continue to complain about the quality of service they receive (Al-Musali \& Ismail, 2014). Customer service employees have long been the medium for providing bank services and their emotional intelligence is clearly one of the key attributes to deliver excellent services and gain customer satisfaction (Collomb, 2018). Therefore, it indicates that Saudi banks need to invest in the emotional intelligence of their customer service employees or face the inevitable consequences. In most Saudi banks, emotional intelligence is not a criterion, but a bonus developed individually by some customer service employees rather than a necessity. Also, customer service employees in some of the Saudi banks suffer from negative job attitudes probably due to emotional labor - which is reflected in how they treat their customers (Naseeb, 2018). The policies and practices of human resource management are implemented to improve job attitudes (Faisal Ahammad et al., 2015) and emotional intelligence remains an essential factor (Salami \& Ajitoni, 2016). This research, therefore, is aimed at examining the effect of customer service employees' emotional intelligence on their job attitudes.

The findings can be used as a reference material by academic researchers interested in further studying the relationship between EI and organizational outcomes of service employees. The results would also aid various organizations, especially the banks, in initiating effective emotional management training programs for the employees to stay ahead of the pack. Furthermore, the results and recommendations of the study would be of great help to Human Resource Managers as well as employers in reviewing their recruitment policies. This will subsequently help identify and employ individuals who have the appropriate emotional orientation to manage the customers. Lastly, this study would add value to the literature that looks into the influencing factor of employees' emotional intelligence on customer service.

\section{Literature Review}

\subsection{Emotional Intelligence}

Researches started to show a great interest in the whole idea of emotional intelligence during the 1800s. Over the years, the ideology of emotional intelligence has evolved, from its rise as "social intelligence" in the 1930s to "emotional strength" in the mid-20th century to the present - "emotional intelligence". The growing interest in the emotional intelligence concept, in recent times, has been driven by Daniel Goleman's book (Goleman, 1996) and its widespread publicity. Such unprecedented acceptance called on a myriad of well-known books and articles that study the application of emotional intelligence and its development in individual and corporation framework. Organizations are showing interest in the EI concept to fulfill their quest for a path to secure a distinct competitive edge that can be built through detailed attention to "others' issues" (Higgs, 1997; Senge, 1990, Ulrich \& Lake, 1990; Sparrow et al., 1994; Kay, 1993). Extensive scientific and research evidence surrounding the idea of emotional intelligence has also known to exist (e.g. Goleman, 1996; Cooper, 1997; Cooper \& Sawaf, 1997). However, there has been limited research in the area of corporate culture, while the available research has greatly been reliant on educational-based research, physiological research developments, and improvements in the therapy fields (e.g. Goleman, 1996; Steiner, 1997; Damasio, 1994). It is imperative to note that derivative arguments and the descriptions of anecdotal cases, in particular, are employed as corporate applications of EI. As a result, the consensus seems to be the difficulty in measuring emotional intelligence. Also, an efficient measurement, as described by Goleman, has not been found (Steiner, 
1997; Hein, 1997). In the upcoming field, the literature consists of a plethora of definitions which might be confusing and. It also includes terms such as emotional literacy (Steiner, 1997), emotional quotient (Cooper, 1997), and personal intelligence. Goleman, nevertheless, offers a reliable definition of the emotional intelligence concept, which refers to:

- Knowing the feelings of an individual and the subsequent ability to manage those feelings without affecting oneself;

- The ability to motivate oneself to complete the job, influence creativity, and perform at ones' best; and

- Understanding the feelings of other individuals and managing relationships effectively.

Adding to the literature, Martinez, 1997, p.72 defines EI as "an array of non-cognitive skills, capabilities, and competencies that stimulate the ability of a person to get through environmental pressures and demands".

The elements of emotional intelligence structure can be summarized as the awareness of one's and others' emotions and the ability to use and handle emotions. A self-aware individual has high self-efficacy and is aware of his/her limits and at peace with him/herself. Besides, such individuals motivate themselves and do not show any negative attitude. High awareness of others' emotions and the sense of empathy are frequently considered in today's business life, which in turn, reveals the significance of emotional intelligence. Salovey et al. (2002) regarded emotional abilities as a key aspect of both social and emotional adaptation. It is generally observed that EI influences innovative behavior (Hu \& He, 2018) along with the quality of worklife. As a result, employees and individuals with a high level of emotional intelligence have positive and productive attitudes. Consequently, this construct is regarded as a crucial skill needed in both professional and social life.

\subsection{Job Satisfaction}

A positive attitude towards one's job or simply job satisfaction unveils the pleasure level of an employee or individual. Important organizational outputs such as high performance, non-conflict environment, and low turnover rate are reliant on an employee's satisfaction from the job and the work environment. Notably, a range of factors affects job satisfaction that can be studied in two separate categories - individual and environmental factors. Age, gender, intelligence, personality, and others form the individual factors. On the other hand, environmental or external factors include wage, management policy, and workfamily conflict (Özsoy, 2015). In the literature, the majority of the studies remain inclined towards the co-relation between the above environmental factors and job satisfaction. However, after a series of research, key factors such as personality, intelligence, and emotional intelligence are more expected to be examined for deeper understanding. Taking this into consideration, Robbins and Judge (2013) highlight that job satisfaction is not limited to work environments and personality also has an important impact on job satisfaction.

\section{$\mathbf{H}_{1}$ : Job satisfaction positively affects the organizational commitment.}

\subsection{Emotional Intelligence and Job Satisfaction}

Individuals with high levels of Emotional Intelligence (EI) are highly likely to encounter more positive emotions and moods as compared to their counterparts with a lower level of EI (Goleman, 1998). It indicates that the latter often translate their emotions to anger and disappointment, which in turn, reduce their total satisfaction. An assumption is that with low level of total satisfaction at the worksite, employees are unlikely to perform at their best which will consequently impact the service rendered to the customer. Guleryuz et al. (2008) used nurses employed in about seven hospitals in Turkey as the research participants to analyzed how their emotional intelligence affects organizational commitment and job satisfaction in the healthcare sector. Their findings revealed a strong positive relationship between EI and job satisfaction.

\section{H2: Emotional intelligence positively affects job satisfaction.}

\subsection{Organizational Commitment:}

Building on the work of Porter and Smith (1970), organizational commitment was defined in an attitudinal manner by Mowday et al. (1979) as "the relative strength of identification and involvement of an individual in a specific organization" (p.226). It goes beyond organizational loyalty to build a more active relationship with the organization in a devotional manner both in beliefs and actions. Moreover, organizationally committed employees are not necessarily free from other commitments in their lives (e.g., family, political party, union ... etc.). Mowday et al. (2013) characterized organizational commitment as:

- Strong belief in organizational values and acceptance of organizational goals

- Willingness to go the extra mile for the sake of the organization

- A high desire for maintaining an organizational membership

On the other hand, Allen and Meyer (1990) introduced the revolutionary "three-component model of commitment" which categorized organizational commitment into three distinct types: 
- Affective commitment (AC): employees' willingness to stay in their organizations

- Continuance commitment (CC): employees' need to stay in their organizations

- Normative commitment (NC): employees' self-obligation to stay in their organizations

The process of delivering a service involves a combination of customer's expectations and behaviour, working conditions, and employees' motivation, knowledge, skills, and abilities (Dollard et al., 2003). The latter will be the center of this study aiming to uncover the co-relation between customer service employees' emotional intelligence and their job attitudes and the interrelations between these attitudes.

\subsection{Emotional Intelligence (EI) and Organizational Commitment (OC)}

In most studies, EI and Organizational Commitment has been found to be positively related (Guleryuz et al., 2008; Zeidner et al., 2004; Mayer \& Salovey, 1997). Further explanation states that individuals showing high emotional intelligence are more likely to be in positive state of mind, resulting in constructive affection towards their organization (Wong \& Law, 2002).

\section{$\mathbf{H}_{3}$ : Emotional intelligence positively affects organizational commitment.}

\subsection{Job Satisfaction and its Mediatory Role:}

The overview of the literature on job satisfaction and organizational commitment revealed many interrelations between these two attitudes. Adeyemo (2007) found that the emotional intelligence of employees mediates the correlation between their job satisfaction and organizational commitment. Simultaneously, Salami (2008) and Miarkolaei and Miarkolaei (2014) concluded that employees' job satisfaction intervenes in the association between their emotional intelligence and organizational commitment. Later on, Güleryüz et al. (2008) explored the part that job satisfaction plays in these constructs and their findings supported the hypothesis, as the significance was not evident prior to introducing job satisfaction to the relationship (Shafiq \& Rana, 2016). A similar conclusion was reached by Naz et al. (2019). This makes the final hypothesis:

$\mathbf{H}_{4}$ : Job satisfaction partially mediates the positive correlations between EI and organizational commitment.

According to the above discussion in the literature review, the relationship between these two constructs of emotions is demonstrated in the conceptual framework of study in Fig. 1

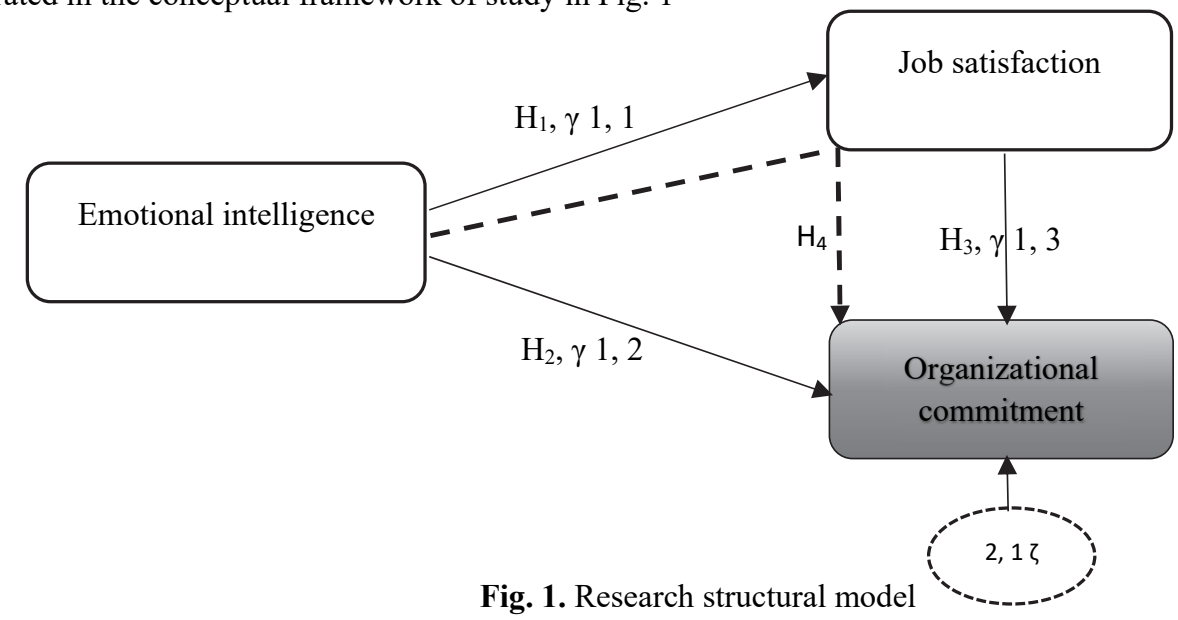

3. Methodology

\subsection{Survey Instruments}

Emotional intelligence (EI): The current study adopts a trait EI scale - WLEIS (Wong and Law Emotional Intelligence Scale). It comprises 16 indicators (four indicators reflecting the four components of emotional intelligence).

Job satisfaction (JS): A single global rating of job satisfaction is simple and captures many discreet elements of this construct, thereby tapping everything needed for consideration (Poon, 2004; Wanous et al., 1997). Therefore, this study adopts the single global rating of job satisfaction with its unique question, "All things considered, how satisfied are you with your job?"

Organizational commitment (OC): The three-component model of organizational commitment (Allen \& Meyer, 1990) is widely used in most of the studies. It views organizational commitment as three types and each of these types has its own scale: The affective commitment scale (ACS), normative commitment scale (NCS), and continuance commitment scale (CCS). Furthermore, each scale consists of 8 items.

Aforementioned measurements were employed on a 7-point Likert scale, with range from (1) strongly disagree to (7) strongly agree. 


\subsection{Data collection}

The study used a self-structured questionnaire to collect the data. Ethical issues were also considered with the assurance of anonymity. The targeted population for the study includes customer service employees working in all main branches of Saudi banks located in Riyadh. The variables were originally developed in English and later translated to Arabic to ensure relevance and enhance the results. The study used the back-translation methodology to improve the linguistic quality and set the conformity of the meaning. A four-member academic panel of management experts from Saudi universities was consulted for the face validity of the questionnaire. Subsequently, necessary modifications were made based on their valuable recommendations. After the preparation of the final copy, a pilot questionnaire was distributed to selected customer service employees and each component of the questionnaire was discussed with them. This helped in ensuring the measurement of each statement. The data was gathered from January to April 2020.

\subsection{Analysis}

After evaluating the answers of the selected participants, Cronbach's alpha method was used to determine the tool's reliability. Moreover, the reliability coefficient alpha $(\alpha)$ was 0.95 determining a high accuracy. Further, Exploratory Factor Analysis from the Statistical Package of Social Science (SPSS 18.0) was employed to assess the pilot data. Additionally, the study used Partial Least Squares-Graph to examine the hypothesized relationships between the variables involved in the study.

\section{Results}

Out of 350 distributed questionnaires, 288 questionnaires were returned, 17 questionnaires were excluded from the analysis due to incomplete answers, and 271 questionnaires were analyzed. A total of 103 females and 97 males were involved in the study. The age distribution specified that a large number of the study participants were aged 20 to 35 , followed by 36 to 45 , and followed by the age above 45 . As shown in Table 1, the descriptive analysis was conducted to track the arrays of data. From the value of standard deviation, it can be seen that the turnover intention values are widely dispersed from the mean value - showing diversity in the responses. Moreover, the value of skewness shows that all the variables are negatively skewed on the normal distribution - showing that most of the responses were on the lower side of the scale as compared to the positive side.

Table 1

Descriptive Statistics

\begin{tabular}{llllllll}
\hline Variables & Mean & Std. Deviation & Variance & Skewness & \multicolumn{2}{c}{ Kurtosis } \\
\cline { 2 - 7 } & Stat. & Stat. & Stat. & Stat. & Std. Error & Stat. & Std. Error \\
\hline Emotional intelligence & 13.534 & 1.3635 & 1.859 & -1.114 & 0.238 & 1.812 & 0.472 \\
Job satisfaction & 12.893 & 2.1093 & 4.449 & -.336 & 0.238 & -.247 & 0.472 \\
Organizational commitment & 25.097 & 4.5986 & 21.147 & -.194 & 0.238 & -.496 & 0.472 \\
\hline
\end{tabular}

A reliability test was carried out to ascertain the reliability of scales employed to measure the variables under study. The results showed that the Emotional intelligence scale has $\alpha=0.84$, Job satisfaction $\alpha=0.81$ and Organizational commitment $\alpha$ $=0.79$. It is imperative to note that the benchmark value for Cronbach's alpha is 0.7 . It indicates that the values obtained for all the sub-scales used in the study are higher than the benchmark value of 0.7 . Thus, it can be concluded that all the subscales used in the study were efficient and measure the intended variable to an acceptable level of satisfaction.

Table 2

Correlation Matrix

\begin{tabular}{llll}
\hline & Emotional intelligence & Job satisfaction & Organizational commitment \\
\hline Emotional intelligence & $\mathbf{0 . 7 0 2 *}$ & & \\
\hline Job satisfaction & 0.687 & $\mathbf{0 . 7 3 9 *}$ & 0.632 \\
\hline Organizational commitment & 0.691 & $\mathbf{0 . 7 1 1 *}$ & \\
\hline
\end{tabular}

Note: *Diagonal values represent the square root of the AVE; all other values denote the correlation coefficients.

Table 2 shows the correlation analysis and suggests that each of the four regression models was remarkable at the $\mathrm{p}<0.000$ level. The average variance extracted (AVE) was calculated to further validate the constructs. AVE reflects "the variance obtained by the construct, given consideration to the variance due to an error in the measurement" (Hair et al., 2006, p. 45). For the construct to have a reliable structure, its minimum AVE value should be 0.50 . From this, it can be concluded that the four variables have good reliability in estimating the latent constructs. As shown in Table 4, other fit indices were also used in the study, as the size of the sample was sensitive with regards to chi-square statistics (Hair et al., 2006). A goodness of fit of the model with data was observed in accordance with various fit indices. The chi-square minimum and the degree of freedom ratio (CMIN/df) was lower that the cut-off criterion of 3.00 (Hair et al., 2006), which indicates a good fit between the data and hypothesized model. Hair et al. (2006) also suggest that the goodness-of-fit index (GFI), adjusted goodness-offit index (AGFI), Bentler-Bonett normed fit index (NFI), Bentler's comparative fit index (CFI), and Tucker-Lewis index (TLI) should all be greater than 0.9. The value of root mean square error of approximation (RMSEA) is also utilized. 
Table 3

Confirmatory factor analysis (CFA) of all measurement models

\begin{tabular}{|c|c|c|c|c|c|c|c|}
\hline CFA Model & Items & CMIN/df & TLI & NFI & GFI & AGFI & CFI \\
\hline Emotional intelligence & 16 & 1.365 & 0.998 & 0.999 & 0.996 & 0.983 & 0.998 \\
\hline Job satisfaction & 1 & 1.235 & 0.996 & 0.997 & 0.997 & 0.967 & 0.998 \\
\hline Organizational commitment & 8 & 1.132 & 0.997 & 0.998 & 0.997 & 0.996 & 0.997 \\
\hline
\end{tabular}

Note: $\mathrm{CMIN} / \mathrm{df}=$ ratio of the chi square minimum to the degree of freedom; TLI = Tucker-Lewis index (TLI); NFI = Bentler-Bonett normed fit index; GFI

$=$ goodness-of-fit index; AGFI = adjusted goodness-of-fit index; CFI = Bentler's comparative fit index

The SEM method was then used to analyze the research model in conjunction with the maximum likelihood estimation method. The intrinsic and extrinsic variables were examined to discover the strength of the proposed model as well as stated hypotheses. The results shown in Table 4 illustrate a right fit of the hypothesized model. The indices demonstrate the goodness of fit of the model, which makes it an authentic factor to evaluate the hypothesized paths. All the fit indices values demonstrate a good fit between the hypothesized model and the data.

Table 4

Goodness of fit of the hypothesized model

\begin{tabular}{|c|c|c|c|}
\hline Measures & & Fit Indices & Value Accepted \\
\hline \multirow{3}{*}{ Absolute Level } & RMSEA & 0.047 & Less than 0.08 \\
\hline & GFI & 0.937 & 0.90 and above \\
\hline & P-value & 0.000 & P-value $\geq 0.05$ \\
\hline \multirow{4}{*}{ Incremental Level } & AGFI & 0.912 & $\leq 0.90$ \\
\hline & CFI & 0.998 & $\leq 0.90$ \\
\hline & TLI & 0.994 & $\leq 0.90$ \\
\hline & NFI & 0.967 & $\leq 0.90$ \\
\hline \multirow{2}{*}{ Parsimonious Level } & $\mathrm{CMIN} / \mathrm{df}$ & 1.136 & $\geq 2.0$ \\
\hline & $R^{2}$ & 0.703 & High is better \\
\hline
\end{tabular}

Note: RMSEA = root mean square error of approximation; GFI = goodness-of-fit index; AGFI = adjusted goodness-of-fit index; CFI = Bentler's comparative fit index; TLI = Tucker-Lewis index (TLI); NFI = Bentler-Bonett normed fit index; CMIN/df = ratio of the chi square minimum to the degree of freedom

\section{Mediating Effect of the Hypothesized Model}

It is observed that the intervention of a third construct or variable between the two related variables results in a mediating effect (see Table 5). The mediatory role of job satisfaction was tested in the association of EI and organizational commitment. The results determine that job satisfaction acts as a partial mediator and has a significant indirect impact of 0.360 that supports the hypothesized model in H4.

\section{Table 5}

Total Effects of mediator in the Research Model

\begin{tabular}{llll}
\hline \multicolumn{2}{l}{ Endogenous Variable (Organizational commitment) } & & \\
\hline & Indirect effect & Direct effect & Total effect \\
Emotional intelligence & 0.360 & $0.237^{* *}$ & $0.597 * *$ \\
\hline
\end{tabular}

\section{Table 6}

Regression Wight for Hypothesized Model Testing Result

\begin{tabular}{|c|c|c|c|}
\hline Hypothesis & Estimate & Critical ratio & Result \\
\hline $\mathrm{H}_{1}:$ Emotional intelligence $\rightarrow$ Job satisfaction & 0.19 & $3.54 * * *$ & Asserted \\
\hline $\mathrm{H}_{2}$ : Emotional intelligence $\rightarrow$ Organizational commitment & 0.21 & $5.11 * * *$ & Asserted \\
\hline $\mathrm{H}_{3}$ : Job satisfaction $\rightarrow$ Organizational commitment & 0.29 & $7.31 * * *$ & Asserted \\
\hline $\mathrm{H}_{4}$ : Emotional intelligence $\rightarrow$ Job satisfaction $\rightarrow$ Organizational commitment & 0.71 & $14.20 * * *$ & Asserted \\
\hline
\end{tabular}

\section{Discussion and Conclusion}

The recent study is aimed at exploring the impact of emotional intelligence on the job satisfaction of customer service employees working in banks in the Kingdom of Saudi Arabia. It further investigates the interactive and mediatory role that job satisfaction imparts on organizational commitment.

The study attempted to contribute to the literature of organizational behavior by displaying a model, especially for managers and researchers to recognize the potential interrelationships between emotional intelligence, job satisfaction, and organizational commitment. Study results showed that scales of Western countries are relevant to an developing economy and eastern country - Saudi Arabia. Measures of these scales indicated that the high validity, reliability, and model results were similar to various studies conducted across developed countries. This study specifically demonstrated the role of emotional recognition. In this study, we found that emotional recognition is related to both job satisfaction and organizational commitment in positive and significant manner. The findings of the structural equation modeling also provided support to this research proposed hypotheses model. This was in accordance with other previous works (Javed et al., 2019; Mérida-López et al., 2019; Papadimitri et al., 2019; Rai \& Tandon, 2018; Naz et al., 2019; Albarq \& Al Doghan, 2020). Emotionally intelligent customer service employees of Saudi commercial banks demonstrated high psychological empowerment visible in how they perceive 
their work as meaningful, increased feeling of competence, guaranteed freedom of choice, and a strong impact on the bank. This finding supports previous works related to this dimension such as Karimi et al. (2018) indicating how emotional intelligence is needed for customer service employees to thrive in the organization. They also seemed to be more engaged in their work, as they believe they are more vigorous, dedicated, and absorbed in their work (Mérida-López et al., 2019, Albarq 2014) as well as more committed to their affiliated banks (Al-khrabsheh et al., 2018; Jain \& Duggal, 2018). Emotional intelligence is an ongoing topic in business and organizational literature, gaining significant attention in both research studies and psychological discussion. Most of these works are directed towards the importance of emotional intelligence to managers and organizational leaders (Kotsou et al., 2018). This study complements the ongoing trend and sheds light on the impact of customer service employees' emotional intelligence on their work.

Further limitations can be addressed by incorporating economic environments, markets, or different demographics. The sample is relatively small and does not represent different sectors of the financial industry. However, the study results can be employed as hypotheses for further studies involving a large number of samples across various geographies in the Saudi economy. It is pertinent to note that future research should emphasize the study of emotional intelligence in the context of customer service employees in banks. This context is of paramount importance for the financial aspect of nations. Banks are the safe-house of residents and a strong engagement and relationship with customers means pleased investment funds. Another opportunity for future research can be the re-application of the study in a different industrial and geographical context. It can also be replicated but with the use of multiple indicators for job satisfaction along with the assessment of all three dimensions of organizational commitment, including affective, continuance, and normative. Possible antecedents of job satisfaction such as stress and organizational justice provide yet another opportunity for upcoming future works.

\section{Acknowledgements}

The author would like to thank the respondents who participated in this study for taken the time to fill in the questionnaire.

\section{References}

Adeyemo, D. A. (2007). Emotional intelligence and the relationship between job satisfaction and organizational commitment of employee in public parastatals in Oyo State, Nigeria. Pakistan Journal of Social Sciences, 4(2), 324-330.

Aki, O. (2006). Is emotional intelligence or mental intelligence more important in language learning?. Journal of Applied Sciences, $6(1), 66-70$

Albarq, A. N., \& Al Doghan, M. (2020). Electronic word-of-mouth versus word-of-mouth in the field of consumer behavior: A literature review. Journal of Critical Reviews, 7(14), 646-654.

Albarq, A. N. (2013). Using structural equation modeling to explore Saudi consumers' intentions regarding counterfeit goods. American Journal of Business and Management, 2(4), 322-331.

Al-khrabsheh, A. A., Muttar, A. K., Mahdi, O. R., Nassar, I. A., AI, S., \& Abdullah II, P. A. H. B. (2018). The impact of organisational factors on organizational commitment at the Arab bank in Jordan. Asian Social Science, 14(7).

Allen, N. J., \& Meyer, J. P. (1990). Organizational socialization tactics: A longitudinal analysis of links to newcomers' commitment and role orientation. Academy of Management Journal, 33(4), 847-858.

Al-Musali, M. A. K., \& Ku Ismail, K. N. I. (2014). Intellectual capital and its effect on financial performance of banks: Evidence from Saudi Arabia. Procedia-Social and Behavioral Sciences, 164, 201-207.

Barsade, S. G., Brief, A. P., \& Spataro, S. E. (2003). Organizational behavior: The state of the science.

Brackett, M. A., \& Salovey, P. (2006). Measuring emotional intelligence with the Mayer-Salovery-Caruso emotional intelligence test (MSCEIT). Psicothema, 18, 34-41.

Brief, A. P., \& Weiss, H. M. (2002). Organizational behavior: Affect in the workplace. Annual Review of Psychology, 53(1), 279307.

Collomb, J. (n.d.). How Employee Satisfaction Drives Customer Satisfaction. Retrieved April 6, 2020, from https://www.myfeelback.com/en/blog/employee-satisfactiondrives-customer-satisfaction.

Cooke, F. L., Cooper, B., Bartram, T., Wang, J., \& Mei, H. (2019). Mapping the relationships between high-performance work systems, employee resilience and engagement: A study of the banking industry in China. The International Journal of Human Resource Management, 30(8), 1239-1260.

Cooper, R. K. (1997). Sawaf. Executive EQ: Emotional intelligence in leadership and organizations.

Cooper, R. K., \& Sawaf, A. (1999). Il fattore emozione. Sperling \& Kupfer.

Dollard, M. F., Dormann, C., Boyd, C. M., Winefield, H. R., \& Winefield, A. H. (2003). Unique aspects of stress in human service work. Australian Psychologist, 38(2), 84-91.

Dou, Y., Ryan, S. G., \& Zou, Y. (2017). The effect of credit competition on banks' loan loss provisions. Journal of Financial and Quantitative Analysis (JFQA), Cambridge University Press.

Faisal Ahammad, M., Mook Lee, S., Malul, M., \& Shoham, A. (2015). Behavioral ambidexterity: The impact of incentive schemes on productivity, motivation, and performance of employees in commercial banks. Human Resource Management, 54(S1), 4562.

Fredrickson, B. L. (2001). The role of positive emotions in positive psychology: The broaden-and-build theory of positive emotions. American Psychologist, 56(3), 218-226.

Goleman, D. (1998). Working with emotional intelligence. Bantam. 
Güleryüz, G., Güney, S., Aydın, E. M., \& Aşan, Ö. (2008). The mediating effect of job satisfaction between emotional intelligence and organisational commitment of nurses: A questionnaire survey. International Journal of Nursing Studies, 45(11), 1625-1635.

Higgs, M. (2004). A study of the relationship between emotional intelligence and performance in UK call centres. Journal of Managerial Psychology.

Jain, P., \& Duggal, T. (2018). Transformational leadership, organizational commitment, emotional intelligence and job autonomy. Management Research Review, 41(9), 1033-1046.

Javed, B., Abdullah, I., Zaffar, M. A., ul Haque, A., \& Rubab, U. (2019). Inclusive leadership and innovative work behavior: The role of psychological empowerment. Journal of Management \& Organization, 25(4), 554-571.

Jordan, G., Miglič, G., Todorović, I., \& Marič, M. (2017). Psychological empowerment, job satisfaction and organizational commitment among lecturers in higher education: comparison of six CEE countries. Organizacija, 50(1), 17-32.

Kamarudin, F., Sufian, F., Nassir, A. M., Anwar, N. A. M., Ramli, N. A., Tan, K. M., \& Hussain, H. I. (2018). Price efficiency on Islamic banks vs. conventional banks in Bahrain, UAE, Kuwait, Oman, Qatar and Saudi Arabia: impact of country governance. International Journal of Monetary Economics and Finance, 11(4), 363-383.

Karimi, L., Leggat, S. G., Donohue, L., Farrell, G., \& Couper, G. E. (2014). Emotional rescue: The role of emotional intelligence and emotional labour on well-being and job-stress among community nurses. Journal of Advanced Nursing, 70(1), 176-186.

Kotsou, I., Mikolajczak, M., Heeren, A., Grégoire, J., \& Leys, C. (2019). Improving emotional intelligence: A systematic review of existing work and future challenges. Emotion Review, 11(2), 151-165.

Mayer, J. D., Salovey, P., \& Caruso, D. R. (2004). TARGET ARTICLES: Emotional intelligence: Theory, findings, and implications. Psychological inquiry, 15(3), 197-215.

Mayer, J. D., \& Salovey, P. (1997). What is emotional intelligence? Emotional development and emotional intelligence: Educational implications, 3, 31.

Mattingly, V., \& Kraiger, K. (2019). Can emotional intelligence be trained? A meta-analytical investigation. Human Resource Management Review, 29(2), 140-155.

Mowday, R. T., Porter, L. W., \& Steers, R. M. (2013). Employee—organization linkages: The psychology of commitment, absenteeism, and turnover. Academic press.

Mérida-López, S., Bakker, A. B., \& Extremera, N. (2019). How does emotional intelligence help teachers to stay engaged? Crossvalidation of a moderated mediation model. Personality and Individual Differences, 151, 109393.

Miarkolaei, H. (2014). An investigation on relationship between employees' job satisfaction and organizational commitment. Management Science Letters, 4(4), 669-678.

Naseeb, I. A. (n.d.). Even Banks Staff. Al-Madina Newspaper. Retrieved December 24, 2019, from https://www.al-madina.com/article/581634.

Naz, S., Li, C., Nisar, Q. A., \& Rafiq, M. (2019). Linking emotional intelligence to knowledge sharing behaviour: mediating role of job satisfaction and organisational commitment. Middle East Journal of Management, 6(3), 318-340.

Özsoy, E. (2015), Türkiye'de İş Tatmini Araştırmalarının Genel Görünümü”, in Özen Kutanis, R. (Ed.), Türkiye'de Örgütsel Davranış Çalışmaları II, Gazi Kitabevi, Ankara.

Papadimitri, P., Staikouras, P., Travlos, N. G., \& Tsoumas, C. (2019). Punished banks' acquisitions: Evidence from the US banking industry. Journal of Corporate Finance, 58, 744-764.

Porter, L. W., \& Smith, F. J. (1970). The etiology of organizational commitment. Unpublished paper, University of California, Irvine, 970.

Poon, J. M. (2004). Effects of performance appraisal politics on job satisfaction and turnover intention. Personnel review.

Rai, A., \& Tandon, D. (2018). Emotional Intelligence \& Job Satisfaction in IT Industry Employee. Asian Journal of Research in Social Sciences and Humanities, 8(5), 139-147.

Robbins, S. P., \& Judge, T. A. (2013). Organizational Behavior. Global.

Salovey, P., Mayer, J. D., Caruso, D., \& Yoo, S. H. (2009). The positive psychology of emotional intelligence.

Salami, S. O., \& Ajitoni, S. O. (2016). Job characteristics and burnout: The moderating roles of emotional intelligence, motivation and pay among bank employees. International Journal of Psychology, 51(5), 375-382.

Shafiq, M., \& Akram Rana, R. (2016). Relationship of Emotional Intelligence to Organizational Commitment of College Teachers in Pakistan. Eurasian Journal of Educational Research, 62, 1-14.

Sparrow, P. (1999). Strategy and cognition: Understanding the role of management knowledge structures, organizational memory and information overload. Creativity and Innovation Management, 8(2), 140-148.

Steiner, C., \& Perry, P. (1997). Achieving emotional literacy: A program to increase your emotional intelligence. Nueva York: Avon.

Ulrich, D., \& Lake, D. G. (1990). Organizational capability: Competing from the inside out. John Wiley \& Sons.

Wanous, J. P., Reichers, A. E., \& Hudy, M. J. (1997). Overall job satisfaction: how good are single-item measures?. Journal of applied Psychology, 82(2), 247.

Wong, C. S., \& Law, K. S. (2002). The effects of leader and follower emotional intelligence on performance and attitude: An exploratory study. The leadership quarterly, 13(3), 243-274.

Zeidner, M., Matthews, G., \& Roberts, R. D. (2004). Emotional intelligence in the workplace: A critical review. Applied Psychology, 53(3), 371-399.

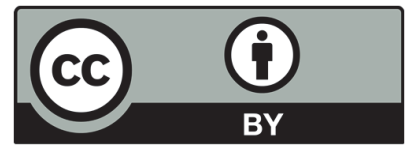

(C) 2021 by the authors; licensee Growing Science, Canada. This is an open access article distributed under the terms and conditions of the Creative Commons Attribution (CC-BY) license (http://creativecommons.org/licenses/by/4.0/). 